\title{
Remote sensing techniques: mapping and monitoring of mangrove ecosystem -a review
}

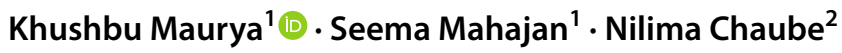

Received: 10 December 2020 / Accepted: 3 July 2021 / Published online: 17 July 2021

(c) The Author(s) 2021

\begin{abstract}
Mangrove forests are considered to be the most productive ecosystem yet vanishing rapidly over the world. They are mostly found in the intertidal zone and sheltered by the seacoast. Mangroves have potential socio-economic benefits such as protecting the shoreline from storm and soil erosion, flood and flow control, acting as a carbon sink, provides a fertile breeding ground for marine species and fauna. It also acts as a source of income by providing various forest products. Restoration and conservation of mangrove forests remain a big challenge due to the large and inaccessible areas covered by mangroves forests which makes field assessment difficult and time-consuming. Remote sensing along with various digital image classification approaches seem to be promising in providing better and accurate results in mapping and monitoring the mangroves ecosystem. This review paper aims to provide a comprehensive summary of the work undertaken, and addresses various remote sensing techniques applied for mapping and monitoring of the mangrove ecosystem, and summarize their potential and limitation. For that various digital image classification techniques are analyzed and compared based on the type of image used with its spectral resolution, spatial resolution, and other related image features along with the accuracy of the classification to derive specific class information related to mangroves. The digital image classification techniques used for mangrove mapping and monitoring in various studies can be classified into pixel-based, object-based, and knowledge-based classifiers. The various satellite image data analyzed are ranged from light detection and ranging (LiDAR), hyperspectral and multispectral optical imagery, synthetic aperture radar (SAR), and aerial imagery. Supervised state of the art machine learning/deep machine learning algorithms which use both pixel-based and object-based approaches and can be combined with the knowledge-based approach are widely used for classification purpose, due to the recent development and evolution in these techniques. There is a huge future scope to study the performance of these classification techniques in combination with various high spatial and spectral resolution optical imageries, SAR and LiDAR, and also with multi-sensor, multiresolution, and temporal data.
\end{abstract}

Keywords Mangroves $\cdot$ Machine learning $\cdot$ Remote sensing $\cdot$ Digital image classification $\cdot$ Mapping and monitoring

\section{Introduction}

Mangroves are a varied group of salt-tolerant plant communities of tropical and subtropical intertidal areas of the globe and act as a natural barrier towards ocean dynamics alongside the shoreline. It occurs especially between latitude $24.0 \mathrm{~N}$ and 38.0 S. The total mangroves cover within the

* Khushbu Maurya

khushbumaurya.ce@indusuni.ac.in

1 Computer Engineering Department, Indus University, Ahmedabad, Gujarat, India

2 Space Application Centre, ISRO, Ahmedabad, Gujarat, India world is 15 million ha which is $1 \%$ of the tropical forests of the globe spread over 123 countries and territories within the tropical and sub-tropical areas and they are found to be rapidly vanishing in many areas.

The mangrove ecosystem has incredible relevance ecologically and economically. Therefore, it is an urgent need for conservation and restoration of the mangrove ecosystem with up-to-date information, planning, and management for it. Typical mangrove habitats may temporarily be submerged due to tides and many times they are found to be located in remote regions. So, the traditional way of field surveys and monitoring methods are time and cost-consuming. In the view of the scenario, time and 
cost-effective mangroves mapping approaches are required which can be made available through remote sensing.

Remote sensing is an efficient method of mapping and monitoring mangroves, due to their visible spectral and spatial signatures which are effortlessly detectable on the satellite images. The mangrove forest covers prolonged over a large area and inaccessible for field surveys can be assessed through remote sensing techniques. Satellite data analysis along with the geographical information system (GIS) is the handiest manner of regularly monitoring the mangrove ecosystem. Furthermore, the application of different classification approaches on remote sensing data acquired through various sensors is useful to extract various parameters of the mangrove ecosystem, such as Tree height, canopy height, above-ground biomass, species structure and types, health of mangroves, leaf area index, leaf chlorophyll content, etc.

With the evolution of satellite imageries and various classification techniques, there is huge scope for the availability of various datasets along with a variety of spectral and spatial characteristics. Which needs different treatment in the context of classifying and extracting different mangroves-related parameters. Therefore, the choice classification approach to extract data from the available satellite image data plays a major role in the evaluation of the mangrove ecosystem. Each classification technique has its characteristics and can be used for a variety of tasks while applying to the mangrove ecosystem for mapping, monitoring, and parameters extraction. In this review, we are focusing on how classification techniques play their role while applying on and combining them with various types of satellite images and sensors to monitor the mangrove ecosystem and to extract parameters. This study aims to find the best possible combination of classification technique, type of image used, and type of sensor used to perform various tasks such as LULC mapping, Change Detection, mangroves biophysical and biochemical parameter extraction and assessment, mangroves health assessment, mangroves spectral signature identification and species discrimination.

There are plenty of research papers available from various geographical locations all over the globe and have used a variety of satellite images along with different sensors and classification techniques to map and monitor the mangrove ecosystem and to extract or estimate the mangrove-related parameters. Here we have studied few key studies among them based on the classification approach used to perform specific tasks, to find the best possible combination of classification approach, type of image used, type of sensor used, and the task performed. Based on this the present study summarizes the above key studies, keeping in mind that the resultant possible combination can be useful for future research to decide,
I. With the availability of specific satellite image data and sensors, which is the best possible classification approach or the combination classification approaches to perform a specific task related to mangroves.

II. In contrast, suppose specific tasks such as mangrovesrelated parameters extraction need to be carried out then which is the best possible combination of classification technique along with satellite image data and sensor as per the availability of dataset for that geographical location.

The main objective of this review is to:

I. Compare the various classification techniques applied for mapping and monitoring of mangroves along with the satellite image used and sensor used.

II. Identify the best combination of classifiers, sensors, and the type of satellite image used to perform various tasks on mangroves while mapping, monitoring, and extracting mangroves parameters.

III. Identify the limitation and gaps of current studies for future scope.

\section{Background of the study}

Remote sensing is the technique of observing objects from a distant place without being in direct contact with the object [58]. It is a procedure of observing the physical characteristics of an area by measuring reflected and emitted radiation at a distance mostly by satellite. There are various approaches to measure the extent of energy reflected, absorbed, and images with appropriate spatial and spectral resolution. A wide variety of spectral information extraction techniques are also available and vary based on the type of data and the use of data.

The mangroves communities are mainly differentiated by their textural and spectral characteristics of the canopy and leaves [59]. These features have a structural appearance, considered to be homogeneous or heterogeneous which depends upon several factors, such as the composition of species, pattern distribution, height, growth density. Mangroves mapping, monitoring, and parameter extraction play a major role in obtaining necessary information on geomorphic and environmental conditions [60]. However, there are certain challenges in assessing mangroves are needed to be resolved by using remotes sensing, such as mangroves are found to be nearby coastal regions, so difficult for field access and sometimes submerged in water, furthermore it is difficult to identify individual trees if their canopies are smaller than the resolution of the 
image if they are found in mixed communities and if they are dense that is species are closely related with identical spectral reflectance.

Remote sensing image analysis is a very important but challenging task however, digital image classification provides a variety of approaches for an image analysis that can be used in combination to extract and analyze various spectral, spatial, and textural features. The generalized flow model for mangrove mapping and monitoring is shown in Fig. 1. Here we are mainly focused on classification and the main goal of digital image classification is to label the pixels with meaningful information of the real world by processing remote sensing image data. These classification approaches analyze the image and place each pixel into a specific category, which is used to derive information of various land features or to group related features and to create a vegetation map, land use land cover (LULC) map. The classification accuracy of any classification approach is based mainly on:

1. Spatial and spectral features of image:

Based on spectral and spatial features the classification approaches are categorized into main two categories which are:

(a) Pixel-based classifiers (classification based on spectral signature and reflectance characteristics)

A pixel-based classification is a traditional approach where each pixel is analyzed based on its spectral characteristics and reflectance. The pixel is a basic measure for satellite images so these methods aim to analyze the pixel values in an

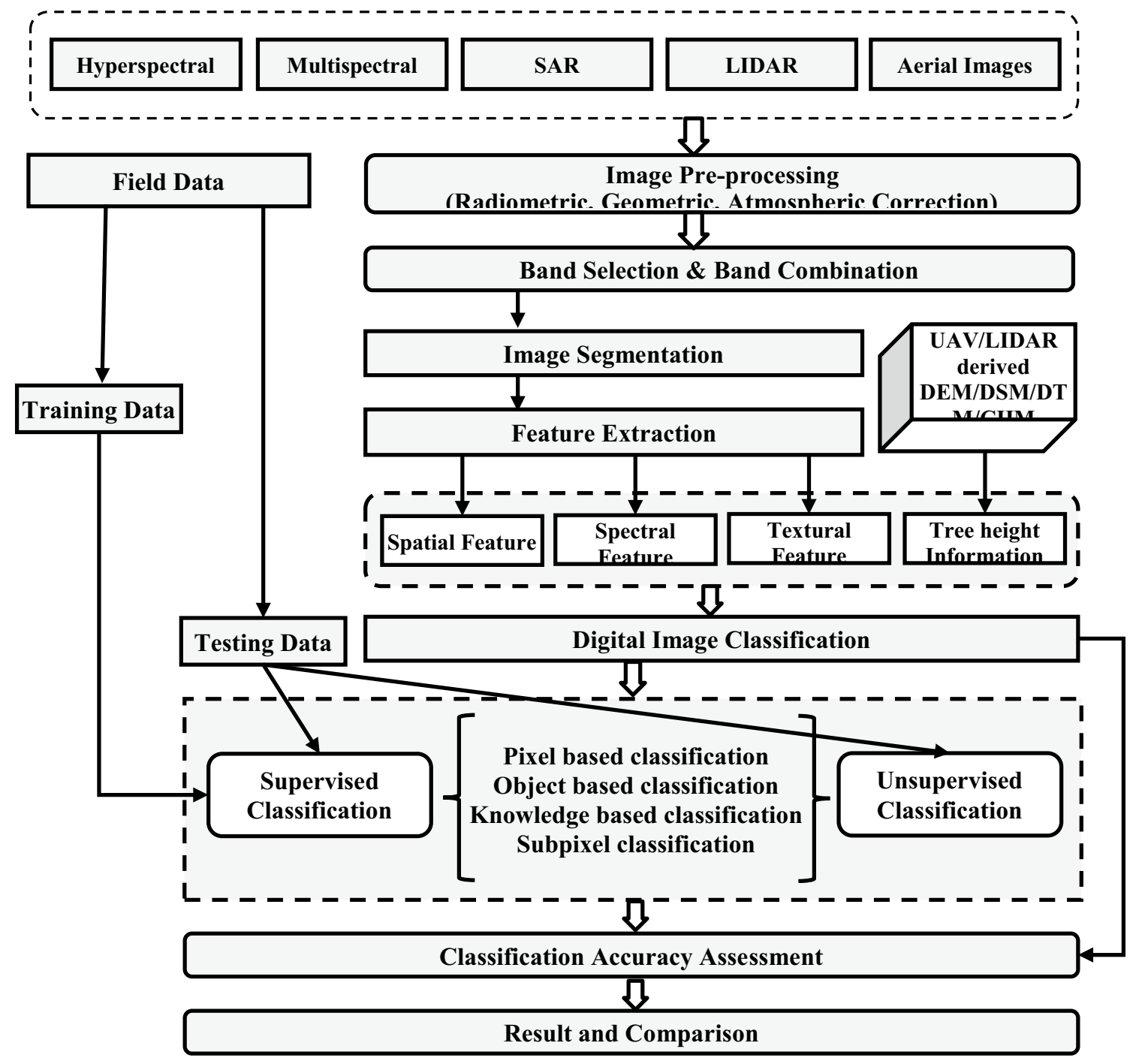

Fig. 1 A generalized flow model for mangrove mapping and monitoring using various digital image classification approaches and remote sensing image data 
image to assign every image pixel to a class based on its spectral characteristic, which is in general known as spectral pattern recognition. The main objective is these methods is to assign all pixels in the image to classify land cover classes such as land, water, forest. The number and type of classes assigned may vary as per the classification method used.

The pixel-based techniques work by defining a feature space that classifies pixels to various classes by creating a scatter plot of spectral values for two bands at a time for all pixel values. Although the features space of an image can have several dimensions, considering one band for each dimension while classifying an image. It is difficult to view all bands together at a time, so possible combinations are two bands plotted separately.

(b) Object-based classifiers(Multiresolution segmentation to delineate the object)

In contrast to pixel-based classification which is solely based on the spectral characteristics of a pixel, Object-based classification uses both spectral and spatial information for classification purposes. In this method set of pixels analyzed based on similar spectral characteristics are called objects. The spectral characteristics of an object can vary from size, shape, and texture and to the context of the neighboring pixel value. Object-based classification methods were considered to be newer as compare to traditional pixel-based classification techniques.

The main goal of this classification to replicate traditional visual interpretation which is done by humans. This technique first applies segmentation to an image which broke the image into different objects and then based on features different objects can be classified. Each object segment contains multiple pixels and is identical to real-world features. Various parameters are taken into consideration while doing the classification process. The most important is the object scale which corresponds to the numbers of pixels that need to be there in a single group to be differentiated by segment or object.

2. Type of learning:

Both methods can further be classified in unsupervised Classification and Supervised Classification based on the learning technique used for training. Learning technique defines the relationship between the data and the information classes and can be categorized as follows:

(a) Supervised classification

In this classification, learning happens through analyzing the pixel information in small sets, which can be selected through human analysts with prior knowledge or based on the map data. These techniques learn through various characteristics of an object and classify various Land cover classes for remote sensing images.

The classification significantly relies on domain knowledge or the expertise of an analyst through which the relationship between different data and classes can be established.

The resultant classification can further be validated through field or ground truth data and the classification accuracy can be evaluated.

(b) Unsupervised classification

Unsupervised classification is helpful when the prior knowledge of field data is unavailable or in absence of an experienced analyst. In this method, data can be analyzed by clustering a similar set of data based on some statistical or mathematical relationship. Therefore, this method is ideally knowns as learning without a teacher.

To identify various classes clustering algorithms are used to analyze the relationship between different data and classes in the unavailability of training data.

In most cases, unsupervised classification is mainly used do a preliminary analysis of data before applying supervised classification

Supervised classification algorithms outperform unsupervised classification when good quality and amount of training data are available.

The classification accuracy relies on spectral, spatial, and textural features extracted from the image data along with the type of learning used. Therefore, it is needed to study various digital image classification approaches applied on past studies of the mangrove ecosystem, that will be helpful in the future to select the appropriate combination of a classification technique and type image data with sensor to be applied on mangroves to perform a specific task related to mangroves mapping monitoring and parameters extraction.

The digital image classification techniques for mangroves are based on direct object delineation i.e. object-oriented, by analyzing pixel characteristics i.e., pixel-based or subpixel-based, and by providing explicit rules along with ancillary data i.e., knowledge-based is categorized and shown in Fig. 2 along with supervised and unsupervised learning. Each classification technique targets differently on the spatial and spectral characteristics of the image to classify the exact object and based 


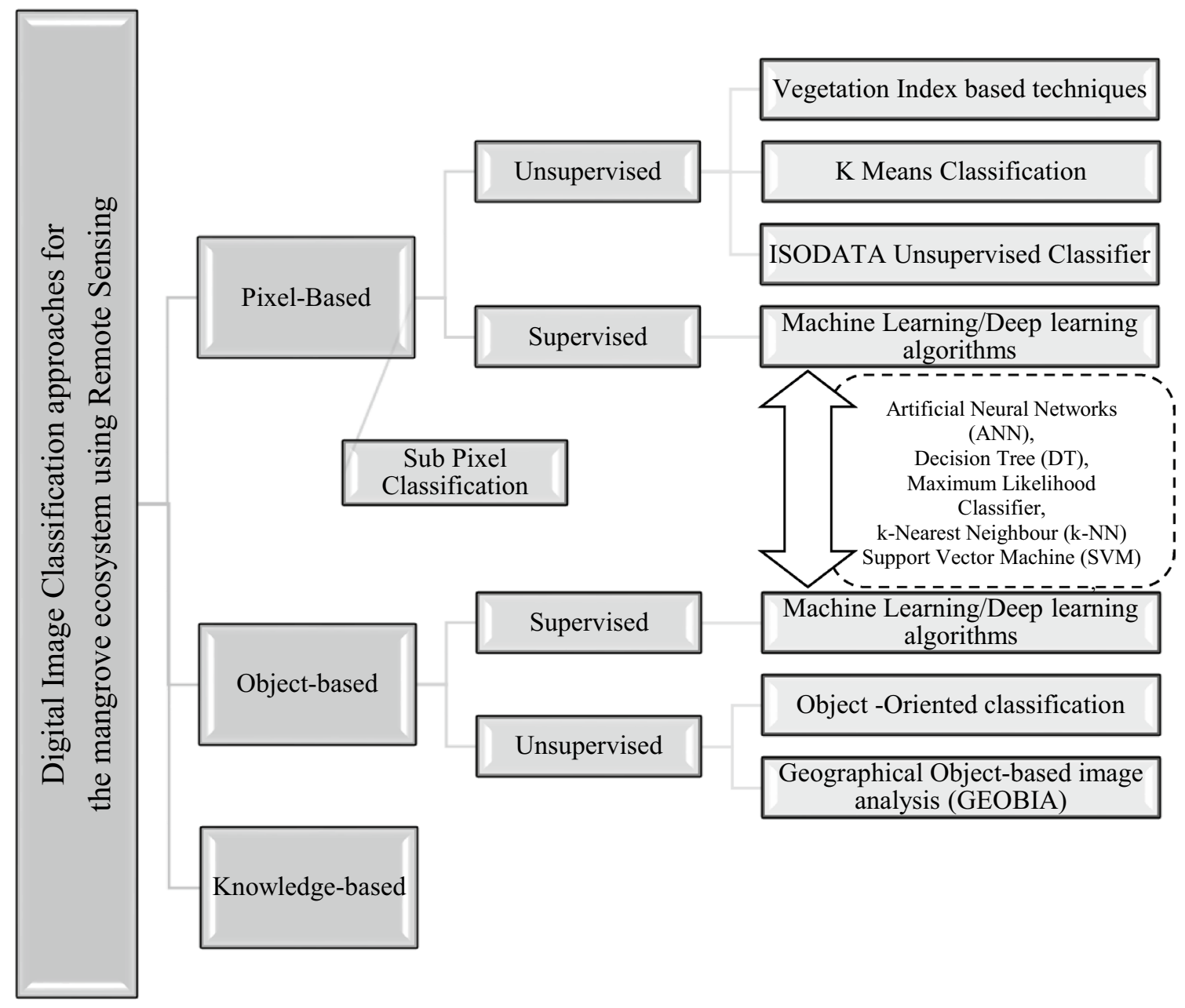

Fig. 2 Digital image classification approaches for the mangrove ecosystem using remote sensing

on these characteristics of data provided classification accuracy may differ.

In the present study, the various classification approaches used for mangrove ecosystem mapping, monitoring, and extracting mangrovesrelated parameters are studied and analyzed considering pixel-based classification, knowledgebased and object-based classification provided with supervised and unsupervised learning for the training dataset. Along with that, each classification approach is studied based on the type of image and sensor used and the task performed along with the accuracy of the task performed. Digital image classification approaches for the mangrove ecosystem using remote sensing.

There are a significantly large number of research studies available that have used various classification approaches for mangroves mapping, monitoring, and parameters extraction. This section reviews key studies on mangroves mapping approaches based on digital image classification techniques along with various remotely sensed image and sensor data used. Furthermore, the hybrid techniques using multiple classification approaches together and using multi-sensor data are also studied and analyzed. The main goal is to find the best possible combination of a classification approach to perform a specific task while using it with various types of satellite images and sensors and vice versa. Here we also focus on the advantages, disadvantages, and comparison of different classification techniques.

\section{Pixel-based unsupervised classifiers}

In the following subsections, pixel-based classification techniques used for mangroves mapping and parameter extraction are explored through various studies.

(a) Vegetation Index-based techniques (Vegetation Indices) 
Index-based techniques are based on various vegetation indices obtained from the remotely sensed image. These techniques provide an effective classification for vegetation cover and can differentiate vegetation from other land cover classes. There is a significant amount of research study available for mangroves in which these techniques are used, few key studies are mentioned in Table 1. The various research shows that these techniques are compatible with different satellite images and sensors such as multispectral and hyperspectral images, as these can be combined with other digital image classification techniques for improved performance.

One of the most favored vegetation monitoring techniques, including mangroves forests, is the Normalized Difference Vegetation Index (NDVI) [13]. Vegetation indices (VI) are a highly used method for estimating land cover variations among different vegetation. hence useful for mangroves too. Furthermore, High spatial resolution imagery can directly delineate vegetation attributes. The key studies for mangroves using this approach are listed in Table 1 . All these vegetation indices are based on a mathematical expression which is various spectral combinations, sensors, platforms, and resolutions used, therefore each one is used for a specific purpose and should carefully be decided based on the application requirement with appropriate validation tools and ground truth data.

\section{Advantages:}

- Calculation of simple vegetation indices combining NIR and infrared band can significantly improve the detection of green vegetation which can be used to classify mangroves area from Non-mangroves area.

- Each VI has its specific expression of green vegetation which can be used to extract various biophysical parameters of mangroves such as leaf chlorophyll concentration (CC) [34], nitrogen concentration. Furthermore, these parameters can be analyzed and used for the health assessment of mangroves.

- The narrow-band vegetation index is also used to predict nitrogen concentrations outperformed by multivariate analyses [35]

- One of the most widely used methods for Land covers land use mapping.

- Can be combined with other supervised and unsupervised approaches for better accuracy and validation purpose.

Table 1 Vegetation Index based techniques

\begin{tabular}{|c|c|c|c|c|c|c|c|}
\hline Technique used & Sensor & Type of image used & Task & Performance & Location & Year & Ref. no. \\
\hline $\begin{array}{l}\text { Narrow-band } \\
\text { vegetation indices } \\
\text { and Multivariate } \\
\text { analyses }\end{array}$ & $\begin{array}{l}\text { Hyperspectral data } \\
\text { HyMap }\end{array}$ & Hyperspectral & $\begin{array}{l}\text { Foliar nitrogen } \\
\text { concentration }\end{array}$ & $\begin{array}{l}\text { The lowest } \\
\text { RMSE of } \\
0.14 \% \text {, vs. } \\
0.25 \% \text { dry } \\
\text { matter }\end{array}$ & $\begin{array}{l}\text { Mahakam delta of } \\
\text { East Kalimantan, } \\
\text { Indonesia }\end{array}$ & 2013 & [35] \\
\hline $\begin{array}{l}\text { Vegetation Indices, } \\
\text { Leave One Out } \\
\text { Cross Validation } \\
\text { (LOOCV) }\end{array}$ & Landsat-8 OLI & Multispectral & Leaf chlorophyll & $\begin{array}{l}(\mathrm{RMSE})=15 \\
\mu \mathrm{g} \mathrm{cm}^{-2}, \text { and } \\
R^{2}=0.703\end{array}$ & $\begin{array}{l}\text { Yucatan Peninsula, } \\
\text { Mexico }\end{array}$ & 2015 & [34] \\
\hline Vegetation Indices & IRS LISS III & Multispectral & $\begin{array}{l}\text { Land Use Cover } \\
\text { Classification } \\
\text { (LULC), man- } \\
\text { groves map gen- } \\
\text { eration manually }\end{array}$ & $91.70 \%$ & $\begin{array}{l}\text { Gujarat, } \\
\text { India }\end{array}$ & 2014 & [9] \\
\hline $\begin{array}{l}\text { Vegetation Index } \\
\text { (NDVI) }\end{array}$ & $\begin{array}{l}\text { Landsat } 8 \text { OLI, } \\
\text { Sentinel-2, } \\
\text { SPOT-5, } \\
\text { WorldView-2 }\end{array}$ & Multispectral & $\begin{array}{l}\text { mangroves Species } \\
\text { Identification and } \\
\text { Classification }\end{array}$ & $\begin{array}{l}64 \%, \\
78 \%, \\
75 \%, \\
93 \%\end{array}$ & Mexican Pacific & 2017 & [43] \\
\hline Vegetation Indices & $\begin{array}{l}\text { AVIRIS-NG, Sen- } \\
\text { tinel-2 }\end{array}$ & $\begin{array}{l}\text { Hyperspectral, } \\
\text { Multispectral }\end{array}$ & $\begin{array}{l}\text { Leaf area index and } \\
\text { stress conditions } \\
\text { for mangroves }\end{array}$ & $\approx 94 \%$ & Sundarban & 2019 & [65] \\
\hline $\begin{array}{l}\text { Discriminant Nor- } \\
\text { malized Vegeta- } \\
\text { tion Index (DNVI) }\end{array}$ & $\begin{array}{l}\text { AVIRIS-NG, Sen- } \\
\text { tinel-2 }\end{array}$ & $\begin{array}{r}\text { Hyperspectral, } \\
\text { Multispectral }\end{array}$ & Health Assessment & $74 \%$-stressed, & Sundarban & 2020 & [66] \\
\hline $\begin{array}{l}\text { New mangrove } \\
\text { vegetation index } \\
(\mathrm{MVI})\end{array}$ & Sentinel-2 & Multispectral & $\begin{array}{l}\text { Mangrove /non- } \\
\text { mangroves cover } \\
\text { discrimination, } \\
\text { statistical analysis }\end{array}$ & $92 \%$ & $\begin{array}{l}\text { Philippines, } \\
\text { Japan }\end{array}$ & 2020 & [67] \\
\hline
\end{tabular}




\section{Limitations:}

- In the context of mangroves, the choice of specific Vegetation Indices needs to be made with caution by comprehensively considering and analyzing the advantages and limitations of existing Vegetation Indices and then combine them to be applied in a specific environment.

- Each vegetation index has its expression of identifying green vegetation, therefore suited for specific purpose and application along with the platform and sensor used.

There is huge scope to develop new vegetation indices for mangrove ecosystem which can find the probability of mangroves in a given area or can directly separate mangroves vegetation from other vegetation with the Multispectral and hyperspectral remote sensing. Also, it is needed to develop vegetation indices that can work on extracting various mangroves' biophysical parameters to broaden the research area.

(b) K Means classifier

The studies for mangrove ecosystem which show the use of $K$ means classification mainly aims to classify land covers. Although the technique can be combined with other supervised algorithms and knowledge-based classifiers to perform a specific mangroves-related task such as mangroves species discrimination, canopy height estimation, forest structure analysis while using various sensors, and remote sensing images. From that few key studies are mentioned in Table 2. $K$ means is an unsupervised classification algorithm that uses minimized mean distance within a cluster. The mean distance is calculated using the sum of the square method between each pixel value along with its assigned center. It is quite similar to ISODATA unsupervised classification but differs in terms that it is sensitive to the initial value. This algorithm best performs with images that have some variance which is not always possible for remote sensing images.

\section{Advantages:}

- Can be used for initial geographical studies of mangroves area when the ground truth data is not available for validation.

- Compatible with various optical imageries, SAR images, and LIDAR and sensors used, to classify land covers and land use for mangroves and forest structure analysis.

- Can be combined with other supervised and knowledge-based techniques to perform a specific task related to mangroves and also provides better accuracy while used in combination with other techniques.

\section{Limitations:}

- As this technique is based on minimized min distance, it is very much sensitive to the initial value assigned for a class, if value contains a mixed pixel which can be possible for mangroves if they are densely combined with other species, then the classification accuracy is poor and for that reason need to be combined with techniques which can

Table $2 K$ means classifier

\begin{tabular}{|c|c|c|c|c|c|c|c|}
\hline Technique used & Sensor & Type of image used & Task & Performance (\%) & Location & Year & Ref. no. \\
\hline $\begin{array}{l}\mathrm{K} \text {-means cluster } \\
\text { analysis }\end{array}$ & Hyperspectral & Hyperspectral & $\begin{array}{l}\text { Mangroves Species } \\
\text { Identification and } \\
\text { Classification }\end{array}$ & $55-74$ & Sundarbans, Indian & 2013 & [45] \\
\hline $\begin{array}{l}\text { K Means, JM-SAM } \\
\text { algorithm, }\end{array}$ & $\begin{array}{l}\text { Hyperspectral } \\
\text { EO-1 Hype- } \\
\text { rion }\end{array}$ & Hyperspectral & $\begin{array}{l}\text { Land Use Cover Clas- } \\
\text { sification (LULC), } \\
\text { mangroves Species } \\
\text { Identification and } \\
\text { Classification }\end{array}$ & $66-88.5$ & $\begin{array}{l}\text { Pichavaram, Muthu- } \\
\text { pet, and Bhitar- } \\
\text { kanika }\end{array}$ & 2014 & {$[28]$} \\
\hline $\begin{array}{l}\text { K-means classifica- } \\
\text { tions, } \\
\text { Fully Constrained } \\
\text { Linear Spectral } \\
\text { Unmixing (FCLSU) }\end{array}$ & $\begin{array}{l}\text { Pleiades-1A, } \\
\text { LIDAR }\end{array}$ & Multispectral & $\begin{array}{l}\text { Mangroves forest } \\
\text { structure analysis, } \\
\text { Canopy height esti- } \\
\text { mation, }\end{array}$ & 78 & $\begin{array}{l}\text { Indian, Atlantic, and } \\
\text { Pacific oceans }\end{array}$ & 2019 & {$[2]$} \\
\hline $\begin{array}{l}\text { K-Means Using HSV } \\
\text { Color Feature }\end{array}$ & Landsat ETM & Multispectral & $\begin{array}{l}\text { Land Use Cover Clas- } \\
\text { sification (LULC) }\end{array}$ & 87-94 & $\begin{array}{l}\text { Dongzhaigang } \\
\text { Mangrove Nature } \\
\text { Reserve, china }\end{array}$ & 2020 & {$[68]$} \\
\hline
\end{tabular}


deal with mixed pixel problem such as subpixel classifier.

- If used alone only suitable for initial analysis of geographical location as being an unsupervised algorithm.

- The results need to be validated through ground truth data, map data, or by the supervised algorithm.

Overall $K$ Means classification is a very simple technique for unsupervised classification purposes, in the future, the performance of this technique with a combination of other techniques can be analyzed and studied for the mangrove ecosystem for the various tasks (Table 3).

(c) ISODATA classifier

Iterative Self Organizing Data Analysis Technique Algorithm (ISODATA) is an unsupervised classification algorithm that is mainly a generalization of the $K$ Means algo- rithm. Here classes are iteratively divided and merged based on the user-defined threshold value. Here each pixel is assigned a class by measuring the Euclidean distance between cluster centers. The working of the ISODATA algorithm is quite similar to the $\mathrm{k}$-means algorithm. The only difference is, k-means classifier needs advance knowledge for the number of classes, and ISODATA allows the different number of classes.

Various research studies for mangroves show the use of the ISODATA classifier for preliminary analysis of the geographical area to study land cover classes. Table 3 summarizes the key studies using the ISODATA classifier for mangroves mapping and monitoring. This algorithm is mostly used when required training data is not available for mangroves or the field access is not possible. ISODATA is mainly used for Land Use Cover Classification (LULC) and change

Table 3 ISODATA classifier

\begin{tabular}{|c|c|c|c|c|c|c|c|}
\hline Technique used & Sensor & Type of image used & Task & Performance & Location & Year & Ref. no. \\
\hline $\begin{array}{l}\text { Unsupervised ISO- } \\
\text { DATA classifier }\end{array}$ & $\begin{array}{l}\text { Quick Bird, } \\
\text { IKONOS }\end{array}$ & Multispectral & $\begin{array}{l}\text { mangroves Species } \\
\text { Identification } \\
\text { and Classification, } \\
\text { tree height, } \\
\text { diameter at breast } \\
\text { height (DBH), leaf } \\
\text { area index }\end{array}$ & $78 \%$ & Guinea, West Africa & 2010 & [44] \\
\hline $\begin{array}{l}\text { Unsupervised ISO- } \\
\text { DATA classifier }\end{array}$ & Landsat & Multispectral & $\begin{array}{l}\text { Land Use Cover } \\
\text { Classification } \\
\text { (LULC) }\end{array}$ & 0.966 & Philippines & 2011 & [32] \\
\hline $\begin{array}{l}\text { Unsupervised ISO- } \\
\text { DATA classifier }\end{array}$ & $\begin{array}{l}\text { Landsat } \\
\text { Enhanced } \\
\text { Thematic } \\
\text { Mapper Plus } \\
\quad \text { (ETM+), } \\
\text { ICESat/ } \\
\text { GLAS } \\
\text { SRTM }\end{array}$ & Multispectral, SAR & $\begin{array}{l}\text { Land Use Cover } \\
\text { Classification } \\
\text { (LULC), Canopy } \\
\text { height estimation, } \\
\text { AGB }\end{array}$ & 0.83 & $\begin{array}{l}\text { Mauritania, Mada- } \\
\text { gascar, } \\
\text { Atlantic } \\
\text { the coast of Western } \\
\text { Africa, }\end{array}$ & 2013 & [26] \\
\hline $\begin{array}{l}\text { Unsupervised ISO- } \\
\text { DATA classifier }\end{array}$ & Landsat 8 & Multispectral & $\begin{array}{l}\text { Land Use Cover } \\
\text { Classification } \\
\text { (LULC) }\end{array}$ & $64-88 \%$ & Philippines & 2018 & [23] \\
\hline $\begin{array}{l}\text { Unsupervised ISO- } \\
\text { DATA classifier }\end{array}$ & $\begin{array}{l}\text { World View, } \\
\text { TanDEM-X high- } \\
\text { resolution imagery } \\
\text { (SAR) }\end{array}$ & Multispectral, SAR & $\begin{array}{l}\text { Land Use Cover } \\
\text { Classification } \\
\text { (LULC), man- } \\
\text { groves Species } \\
\text { Identification and } \\
\text { Classification, } \\
\text { Canopy height } \\
\text { estimation }\end{array}$ & 89.33 & Sundarban & 2019 & [6] \\
\hline $\begin{array}{l}\text { Unsupervised ISO- } \\
\text { DATA classifier }\end{array}$ & $\begin{array}{l}\text { Landsat } 8 \text { OLI and } \\
\text { Landsat } 5\end{array}$ & Multispectral & $\begin{array}{l}\text { Change Manage- } \\
\text { ment, mangroves } \\
\text { degradation }\end{array}$ & $77-81 \%$ & $\begin{array}{l}\text { Pahang River, } \\
\text { Pahang state, } \\
\text { Malaysia }\end{array}$ & 2019 & [29] \\
\hline
\end{tabular}


management, although while combined the same with Digital Elevation Model and other related models provide good results for mangroves canopy height estimation, tree height estimation, and above-ground biomass calculation.

\section{Advantages:}

- Can be used for preliminary studies of mangroves area when the ground truth data is not available as the algorithm does not require a training class for classification [23].

- Provide improved performance as compared to $K$ means in most of the cases.

- Compatible with various optical imageries, SAR images, and LIDAR and sensors used, to classify land covers and land use for mangroves and forest structure analysis.

- Can be combined with other supervised and knowledge-based techniques to perform a specific task related to mangroves and also provides better accuracy while used in combination with other techniques.

\section{Limitations:}

- The results need to be validated through ground truth data, map data, or by the supervised algorithm.

- If used alone only suitable for initial analysis of geographical location as being an unsupervised algorithm.

ISODATA classification is simply a modification of $K$ Means classification and performs better than $K$ Means in most cases, in the future the performance of this technique with the combination of other techniques can be analyzed and studied for the mangrove ecosystem for the various tasks.

\section{Subpixel classification}

As the pixel is a basic measure for satellite image and so pixel-based classification is easy to implement but there are few limitations of this technique, one is information from nearby pixels are not used to form a class, which leads to misclassification and second is this technique does not provide satisfactory results with mixed pixels. The pixel is considered to be the smallest spatial area for classification, most of the classification algorithms perform classification considering each pixel contains homogeneous data and also belongs to a single class. But in reality, a pixel may contain values for multiple classes, are known to be mixed pixels. A mixed pixel problem can be solved by the subpixel classifier which is a technique to identify multiple classes in a single pixel.

Sometimes mangroves are closely related to other vegetation and canopy gaps are too small in this case a pixel may contain a value of more than one class, which leads to a mixed pixel problem. Due to this the pixel which contains more than one class shows a significant variation in terms of spectral brightness, hence averaged pixel value does not represent an accurate class, which results in misclassification or it may degrade the accuracy of classification. The mixed pixel problem is a big concern while classifying mangroves-related parameters. Few key studies to solve mixed pixel problem using subpixel classification is mentioned in Table 4.

Many techniques are implemented to unmix the spectral information within a pixel. Some of the common techniques are Spectral unmixing and Fuzzy classification. Sub-pixel classification is used to identify the proportions of the different land cover classes within a pixel while Fuzzy classification allows pixels to be a part of multiple classes by calculating a degree of membership for each class. Pixel unmixing can be supervised or unsupervised and linear or nonlinear. In the supervised case, end-member signatures are known, but the estimation of their abundances is required. In the unsupervised case, both the number of end-members and their signatures need to be estimated before abundance estimation.

Subpixel Classification significantly solves mixed pixel problems by identifying different material within the single-pixel using linear spectral unmixing and gives fraction images of each land cover class so that homogeneous species of mangroves can be classified well [46]. This method provides good results in identifying and classifying mangroves species and also results satisfactory for mangroves health assessment. But in [20] Spectral Angle Mapper (SAM) and Object-Based Image Analysis (OBIA) outperform this method significantly.

\section{Advantages:}

- Can be used to discriminate mangroves having homogeneous species.

- Can be used to distinguish mangroves from other species while canopy gaps are too small.

- Can separate multiple classes within a pixel which can be further useful in mangroves health assessment.

- Can be useful with the sensors having higher spectral resolution but coarser spatial resolution which may lead to mixed pixel problem. 
Table 4 Subpixel classifier

\begin{tabular}{|c|c|c|c|c|c|c|c|}
\hline Technique used & Sensor & Type of image used & Task & Performance & Location & Year & Ref. no. \\
\hline $\begin{array}{l}\text { Linear spectral } \\
\text { unmixing (LSU), } \\
\text { Object-based image } \\
\text { classifier (OBIA), } \\
\text { Spectral Angle Map- } \\
\text { per (SAM) }\end{array}$ & $\begin{array}{l}\text { Hyperspectral } \\
\text { CASI-2 }\end{array}$ & Hyperspectral & $\begin{array}{l}\text { Mangroves Species } \\
\text { Identification and } \\
\text { Classification }\end{array}$ & $\begin{array}{l}\text { LSU-56\% } \\
\text { SAM-69\% } \\
\text { OBIA-76\% }\end{array}$ & $\begin{array}{l}\text { Southeast Queens- } \\
\text { land, Australia }\end{array}$ & 2011 & {$[20]$} \\
\hline $\begin{array}{l}\text { Subpixel Classifica- } \\
\text { tion/ } \\
\text { Constrained and } \\
\text { unconstrained } \\
\text { Linear spectral } \\
\text { unmixing (LSU) }\end{array}$ & $\begin{array}{l}\text { Hyperspectral Hype- } \\
\text { rion }\end{array}$ & Hyperspectral & $\begin{array}{l}\text { mangroves Species } \\
\text { Identification and } \\
\text { Classification }\end{array}$ & $68 \%$ & $\begin{array}{l}\text { Sundarbans Delta, } \\
\text { India }\end{array}$ & 2013 & [46] \\
\hline $\begin{array}{l}\text { Pixel-based methods } \\
\text { Linear spectral } \\
\text { unmixing (LSU) }\end{array}$ & $\begin{array}{l}\text { Hyperspectral } \\
\text { CASI-2 }\end{array}$ & Hyperspectral & $\begin{array}{l}\text { mangroves Species } \\
\text { Identification and } \\
\text { Classification, } \\
\text { Health Assessment }\end{array}$ & $90 \%$ & Mexico & 2014 & [10] \\
\hline $\begin{array}{l}\text { Linear Spectral } \\
\text { Unmixing }\end{array}$ & EO-1 Hyperion & Hyperspectral & $\begin{array}{l}\text { Change Detection of } \\
\text { mangroves Species }\end{array}$ & $80 \%$ & $\begin{array}{l}\text { Henry island, } \\
\text { Sunderban Deltaic } \\
\text { region of West } \\
\text { Bengal, India }\end{array}$ & 2018 & {$[61]$} \\
\hline $\begin{array}{l}\text { Fully constrained } \\
\text { linear spectral } \\
\text { unmixing, } \mathrm{K} \text { means }\end{array}$ & LIDAR, Pleiades-1A & Multispectral & $\begin{array}{l}\text { mangroves Species } \\
\text { Identification and } \\
\text { Classification }\end{array}$ & $78 \%$ & $\begin{array}{l}\text { Indian, Atlantic, and } \\
\text { Pacific oceans }\end{array}$ & 2019 & {$[62]$} \\
\hline
\end{tabular}

\section{Limitations:}

- The limitation of this method is the number of classes cannot exceed the number of input bands.

- Object-based classification may outperform this technique as works on an object of interest rather than pixel value.

\section{Pixel-based/object based supervised classification techniques (machine learning/deep learning based algorithms)}

Recent development in artificial intelligence, Image processing, and computer vision resulted in advanced machine learning and deep algorithms which falls into the category of pixel-based/object-based supervised classification. With the development of machine learning algorithms, many new classification models have been produced and provide more choices for the classifications of remote sensing images. The various mangroves research studies show most of these are compatible with multispectral, hyperspectral, and Synthetic Aperture Radar (SAR) images along with different sensors and can be used to perform different mangroves classification tasks. Although each algorithm has its suitability and advantages when applied to the mangrove ecosystem.

Supervised classification is mostly based on implicit rules and includes neural networks, machine learning, and deep learning approaches for classification. Various studies on mangroves found which use artificial neural networks
(ANN), decision tree (DT), K nearest neighbor (KNN), maximum likelihood classifier (MLC), support vector machine (SVM), random forest (RF), and rotation of forest (RoF) algorithms for classification purpose. From which MLC is parametric while all others are non-parametric. These algorithms provide satisfactory results in identifying mangroves species as well as mangroves-related parameters when used in combination with textural and spectral features. Few key studies based on these algorithms are summarized in Table 5 and observations from each algorithm are mentioned below.

\section{Artificial neural network (ANN)}

ANN uses multilayer feedforward networks and various backpropagation algorithms for self-learning of features, various deep learning approaches can also be combined with ANN for training purposes. As ANN can learn the features by itself, the studies show the use of these algorithms to extract various mangroves-related parameters, species discrimination as well as it can be used for change management.

For mangroves species discrimination it is very difficult to design hand-crafted features as they are having varying structures, that is where we need the classification approach which can derive features by itself and no need to input the features. Deep learning neural networks such as convolutional neural networks (CNNs) can solve this problem, the only limitation is the training needs large training data to train the network. Although this limitation can be tackled 


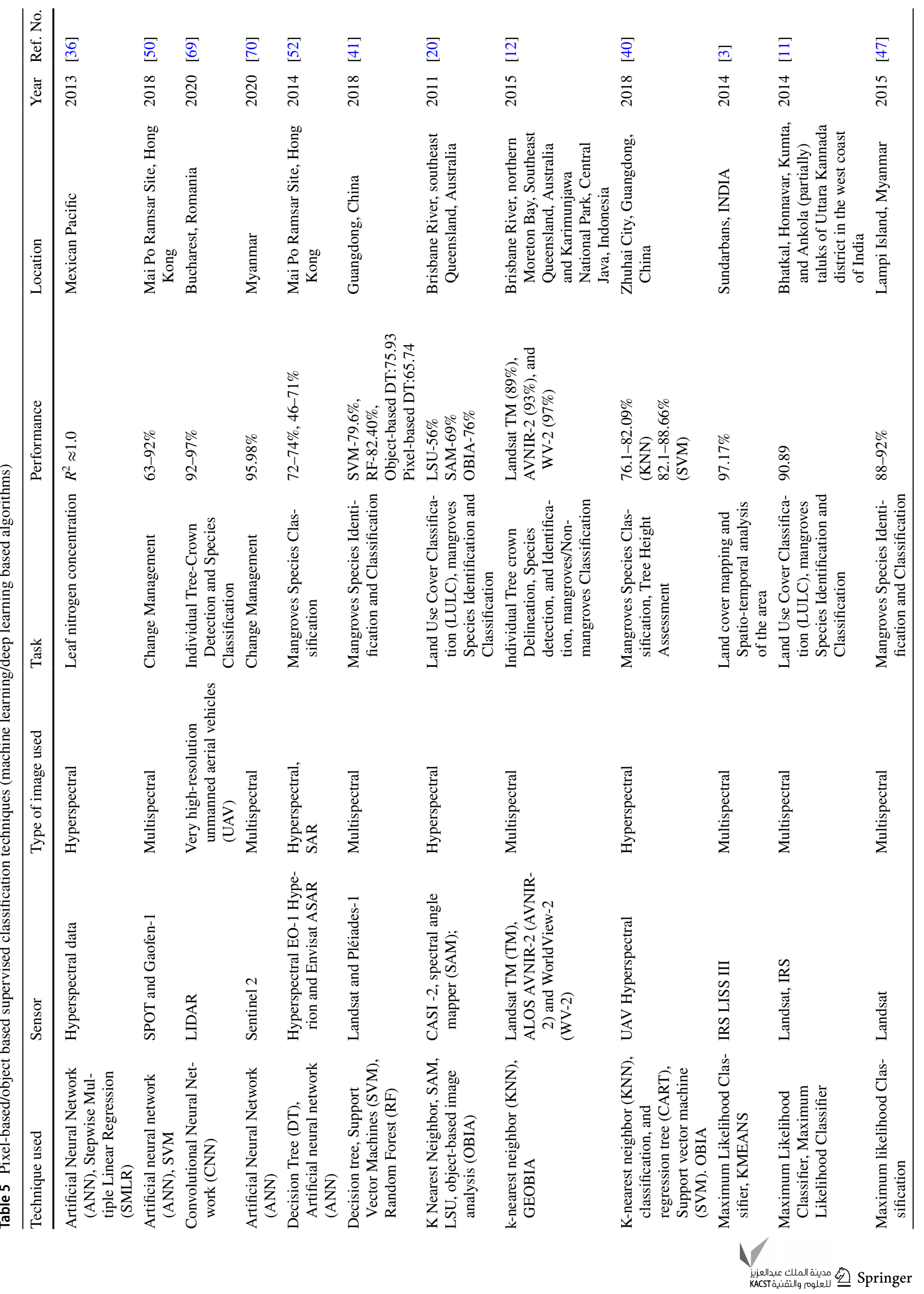




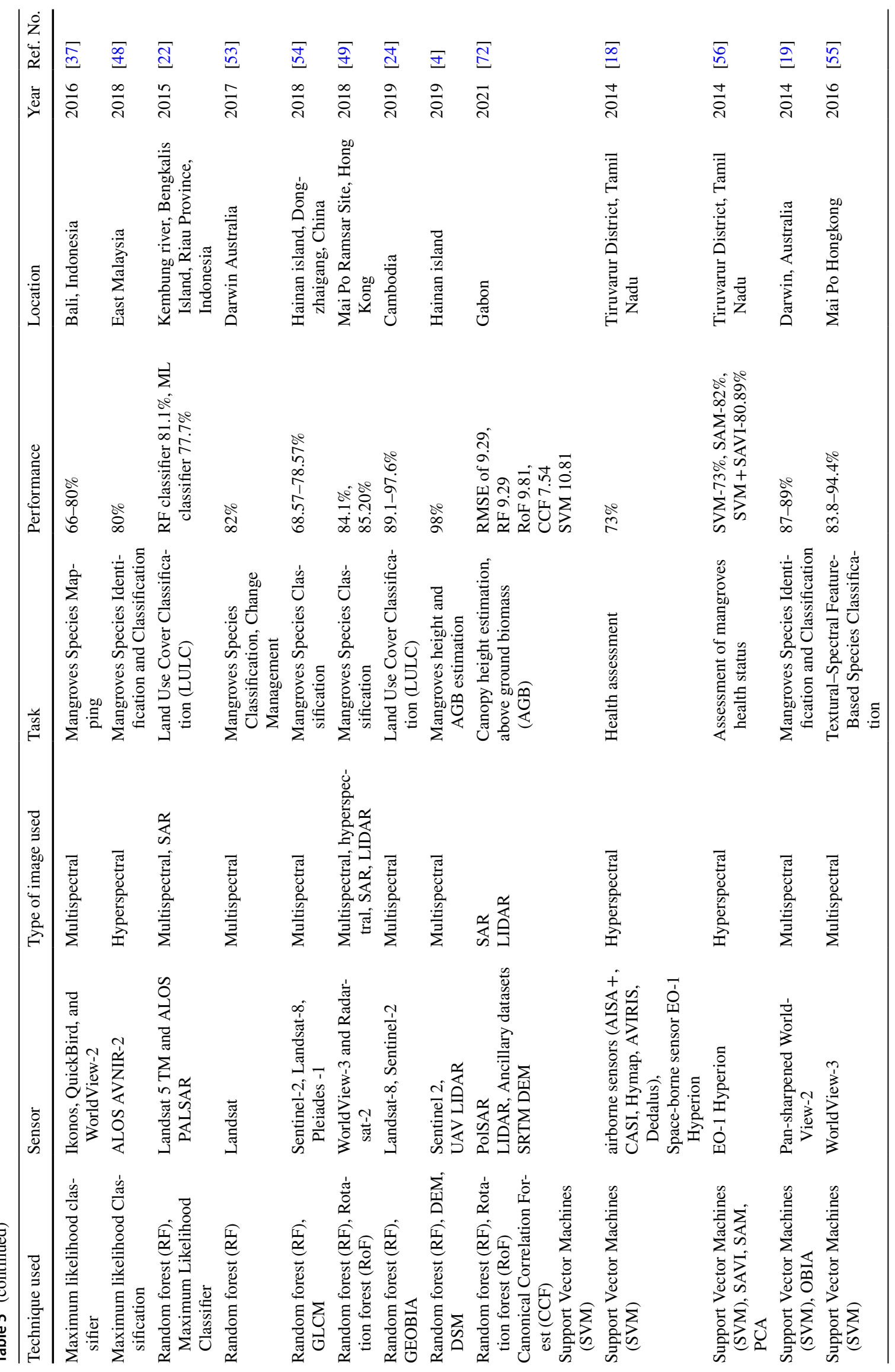




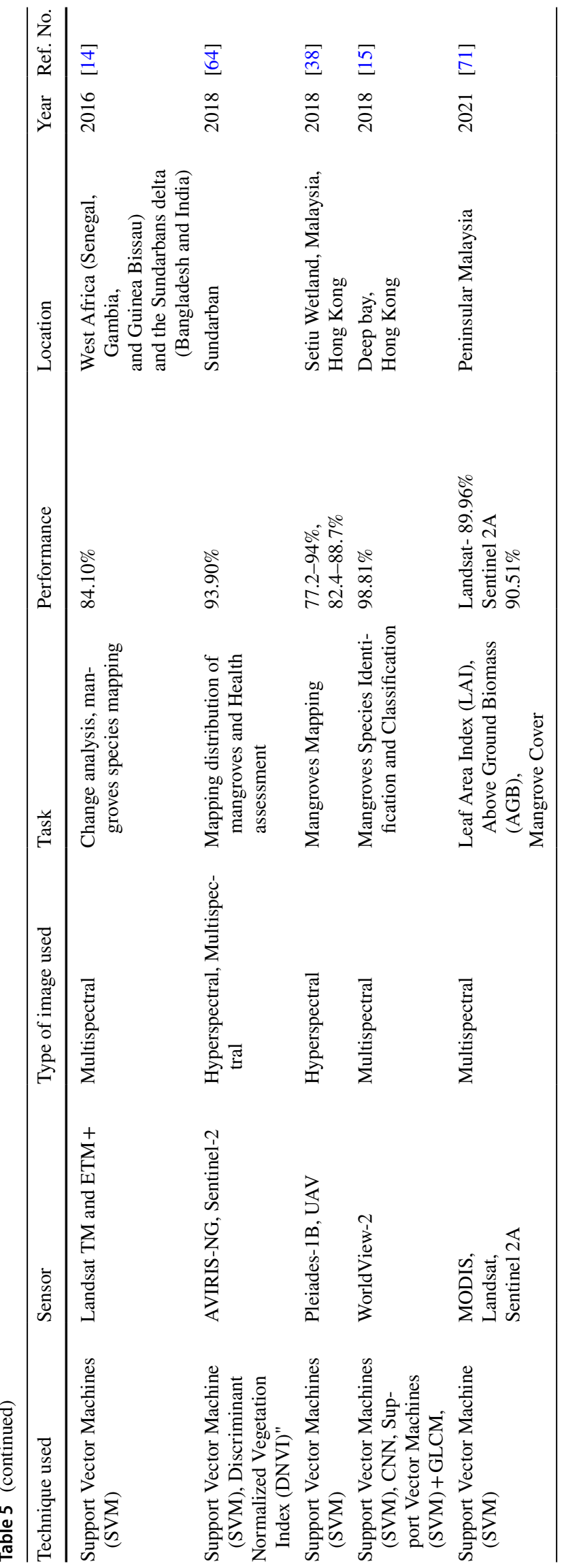

by Small patched CNNs as mentioned in [15]. Also, the study has recorded the highest accuracy of SVM $98.81 \%$ when combined with this deep learning-based convolutional neural network $(\mathrm{CNN})$ and gray level co-occurrence matrix (GLCM) with World view two sensors.

ANN are yet evolving with the recent developments in deep learning and computer vision-based technologies, so there is a huge scope of applying these approaches for the mangroves studies future along with the supervised machine learning techniques for self-learning of features, which can provide more accurate results for the classification.

\section{Decision tree}

This classification technique performs well by selecting object features while providing an optical segmentation scale. This characteristic of a decision tree is helpful in the discrimination of mangroves species which shows satisfactory results in most of the cases. The formation of a decision tree plot is useful to learn how the classification is done step by step and how each object's features and values are correlated at each node. The only limitation of this classification technique is that DT is sensitive to segmentation scale change. Due to this the performance of classification when applied to complex mangroves species or mixed mangroves species. Studies also reported DT sometimes overfit the model while training which can lead to misclassification and reduces accuracy.

\section{k-Nearest neighbor (k-NN)}

This classification technique is a distance-based, non-parametric model, here the $k$ nearest pixels are analyzed to form a class having similar features. Due to that, this choice of $k$ value plays a major role in this classification. Classification accuracy may vary based on the $k$ value. $k$-NN provides better results in identifying mangroves species, health assessment, and individual tree crown delineation while used along with other classifiers such as Object-based classifier and Support Vector Machine [12, 40]. The accuracy of classification also depends on the training data provided and most of the studies show that the higher the training data, the higher the accuracy.

\section{Maximum likelihood classifier (MLC)}

The maximum likelihood classifier is one of the most popular methods of classification in remote sensing and is also widely used for mangroves studies although that does not prove it to be the best method. MLC is also a distance-based

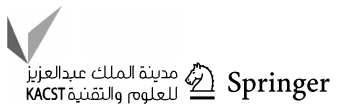


method that uses Euclidean distance to calculate pixel likelihood. The pixel likelihood is defined by the probability of a pixel belonging to a class. Due to this, the method fails to separate mixed classes of vegetation classes. mangroves with mixed species and with closely related canopy gaps cannot be accurately classified by this method. Also, MLC requires a sufficient amount of ground truth data for validation, which sometimes difficult with dense mangroves forest area and when the part of the area is submerged in the ocean. One of the major limitations of MLC for mangroves classification is distribution, When the distribution of the population does not follow the normal distribution, the maximum likelihood method cannot be applied. Although the classification techniques can be combined with other classifiers to gain improve results for a task like mangroves species discrimination along with high spatial and spectral resolution image data (Table 5).

\section{Support vector machine (SVM)}

In contrast to the decision, tree SVM seems to be stable with scale variation and is also works by selecting object features for the classification purpose. Various studies show that this algorithm works well even if having limited training data as compare to other algorithms. SVM can also be used for mangroves species discrimination as well as mangroves health assessment. SVM also shows good performance on mixed mangroves species over decision tree classification as it is having the capability to locate optimal separating hyperplane with high dimensional features. Although it seems to have more advantages as compared to other algorithms, SVM has few limitations on the selection of key parameters which are mainly called kernel function and penalty parameter. If these values are too small then classification results in overfitting. In contrast, if the values are too large there may problem of underfitting or over smoothing. Most of the time researchers have determined these values on a trial-and-error basis. After Maximum Likelihood Classifier(MLC), Support vector machine is the most widely used algorithm for mangroves studies, it provides good results in textural-spectral feature-based species classification, health assessment, change management, and land cover mapping $[14,15,16$, $18,19,21,38,41,55]$.

\section{Random forest (RF) and rotation of forest (RoF)}

$\mathrm{RF}$ is an ensemble classifier and stable to the segmentation scale variation, unlike DT. RF seems to be powerful while selecting object features and can handle high-dimensional data. Although various studies show as compare to the other machine learning algorithms, RF is sensitive to the size of training data and sampling. It shows higher accuracy over a larger training dataset. RF can work well with mixed mangrove species when used with an object-based approach. RF is recommended from the studies for the mangrove species discrimination along with high spatial resolution data.

The limitation of RF can be solved by the Rotation of the forest algorithm which works similarly but performs better with the use of small decision trees for relatively smaller training data. This method also generates ensembles based on feature extraction and then the feature set is divided into $k$ subsets and Principal Component Analysis (PCA) is applied to each $k$ subset. All PCA may represent various information related to data, application of rotation over $k$ components forms a new feature set which in result improve the accuracy of classification.

ANN, RF, RoF, and DT individually and in combination with other algorithms are used to assess biophysical parameters of mangroves such as leaf nitrogen concentration, Leaf Area Index (LAI), leaf chlorophyll concentration [36, 52]. These algorithms also provide good results in estimating Above Ground Biomass(AGB), mangroves health assessment, individual tree crown delineation, and canopy height estimation and species identification [4, 12, 18, 40, 51-53]. Random forest (RF) with sentinel 2 provides the highest accuracy of $98 \%$ in estimating tree height and Above Ground Biomass (AGB) in [4].

\section{Unsupervised object-based classification}

When applied to the mangrove ecosystem, Pixel-based analysis is a simple method across the sensors but sometimes unable to delineate Individual tree crowns and Canopy gaps which are having multiple pixels and produce correlation with objects to be detected by sensors. In these cases, most of the time pixel is not a unit of interest, and therefore object-based classification is used. This creates meaningful objects by doing segmentation of images and grouping pixels with similar spectral and spatial characteristics. These segmented objects are further used for analysis through which spectral and spatial information related to mangroves features can be extracted. Later based on the feature set classes can be generated. These approaches are mainly classified into object-oriented classification and Geographical Object-based image analysis (GEOBIA). These techniques are useful for Individual tree crown delineation, species discrimination, change management, and time-series data analysis. Table 6 shows some key studies based on these two classification techniques.

\section{Advantages:}

- Can work well with mixed pixel, so easily differentiate between canopy gaps, and can be used for individual tree crown delineation for mangroves. 


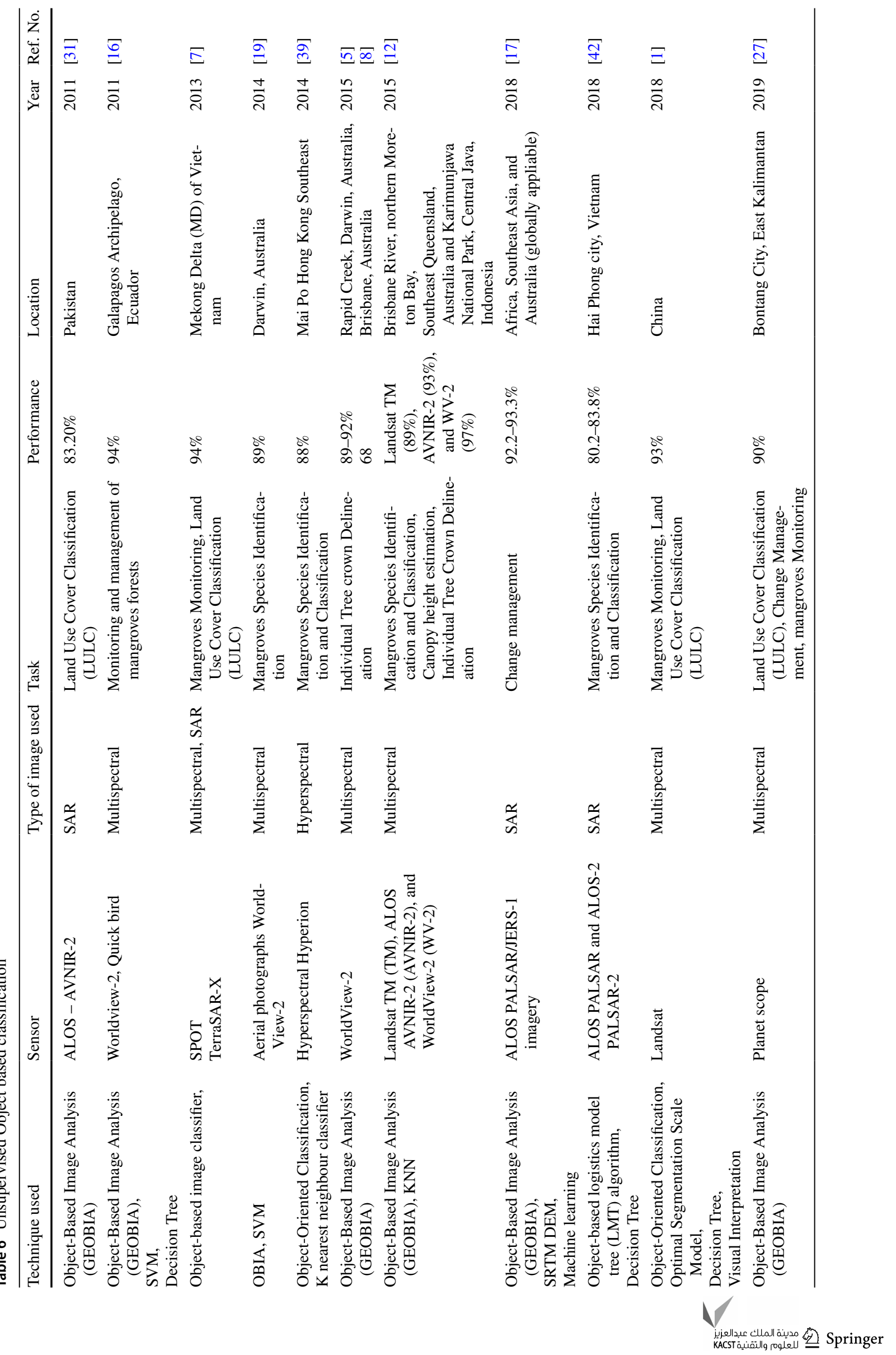


- Work directly to analyze a set of neighboring pixels as an object in contrast with traditional pixel-based approaches that work on individual or sub-pixel values.

- Compatible with a variety of sensors and images but provide better performance over high spatial and spectral resolution data such as Hyperspectral images.

\section{Limitations:}

- Performance of classification may get degraded with low spectral or spatial resolution data.

- Provide better performance in combination with other supervised classification techniques.

\section{Knowledge-based classification}

The Knowledge-based classification approach is very helpful when the spectral characteristics are not enough to identify classes, that is when explicit rules and other types of data are needed to be included in the classification in form of required knowledge. The knowledge can be acquired from ancillary data in addition to spectral information, which is geographic map data, thematic maps, and Digital Elevation Model (DEM) with elevation, slope angle, explosion details, etc. these details can be used to establish the relationship between classes and ancillary data.

Knowledge-based classification is an analysis based on explicit rules to extract knowledge from a given input. In this classification approach, first image segmentation is performed by using object-oriented classification. The next image is divided into consequential pixel groups called segments. To describe each class, a set of knowledge-based classification rules based on spectral, spatial, contextual, and textural characteristics are defined by the user. Lastly chosen classifier assigns each segment to the appropriate class by using a set of rules defined earlier. This method is used for mangroves studies along with digital elevation model (DEM), digital surface model (DSM), spectral angle mapper (SAM), and gray level co-occurrence matrix (GLCM) individually or in combination with other classification approaches as shown in Table 7. This model significantly reduces error due to misclassified data and hence improves accuracy.

The performance of knowledge-based classification is solely based on the relationship between class and ancillary data, based on that the classification proceeds for further decision making. Therefore, this method is only applied or useful when the relationship between the classes of image and ancillary data.

\section{Advantages:}

- Very helpful in assessing mangrove-related parameters such as canopy height estimation, tree height, and diam- eter estimation, above-ground biomass estimation using DEM.

- Compatible with a variety of sensors and images especially SAR, LIDAR, and hyperspectral and provide better performance over high spatial resolution data.

- When combined with state-of-the-art machine learning and deep learning techniques provides improved results on training data.

\section{Limitations:}

- Performance of classification is mainly dependent on related class and ancillary data, if the relationship is not formed properly performance of classification is not accurate.

- Availability of ancillary data and, also classification needs handcrafted explicit rules whose accuracy depends on the experience and expertise of analysts.

\section{Summary of mangroves mapping methods using remote sensing}

While the traditional mangrove mapping techniques are complex, time-consuming, and struggled to assess various parameters of the mangrove ecosystem, the digital classification approaches show satisfactory results by analyzing their spectral, spatial, and textural characteristics for the various parameters such as species structure, spatial distribution, canopy density, gaps between canopies, tree height and diameter, leaf pigments and disturbance. The choice of satellite image and sensor plays a major role in digital image classification to get better spatial, spectral, and textural characteristics of an image. Based on that we have summarized some of the recommendations from past studies as mentioned in Table 8, mainly for various tasks that need to be performed on mangroves while mapping, monitoring, and parameter extraction.

From the observations of past studies, it can be summarized that low and medium-resolution imageries with unsupervised pixel-based vegetation indices, $K$ means and ISODATA work well for initial studies mainly for land cover land use classification and change management. Optical imagery, SAR, and LIDAR data are most widely used in mangroves classification approaches. Studies have concluded that multispectral data can cover larger areas and used for land cover land use classification and change management. Although hyperspectral data with high spatial resolution provides higher accuracy in the classification of mangroves it can cover a limited area. So, for smaller areas, hyperspectral data becomes a better option than multispectral imagery. Further studies can be done with supervised techniques for mangrove biophysical parameters extraction 


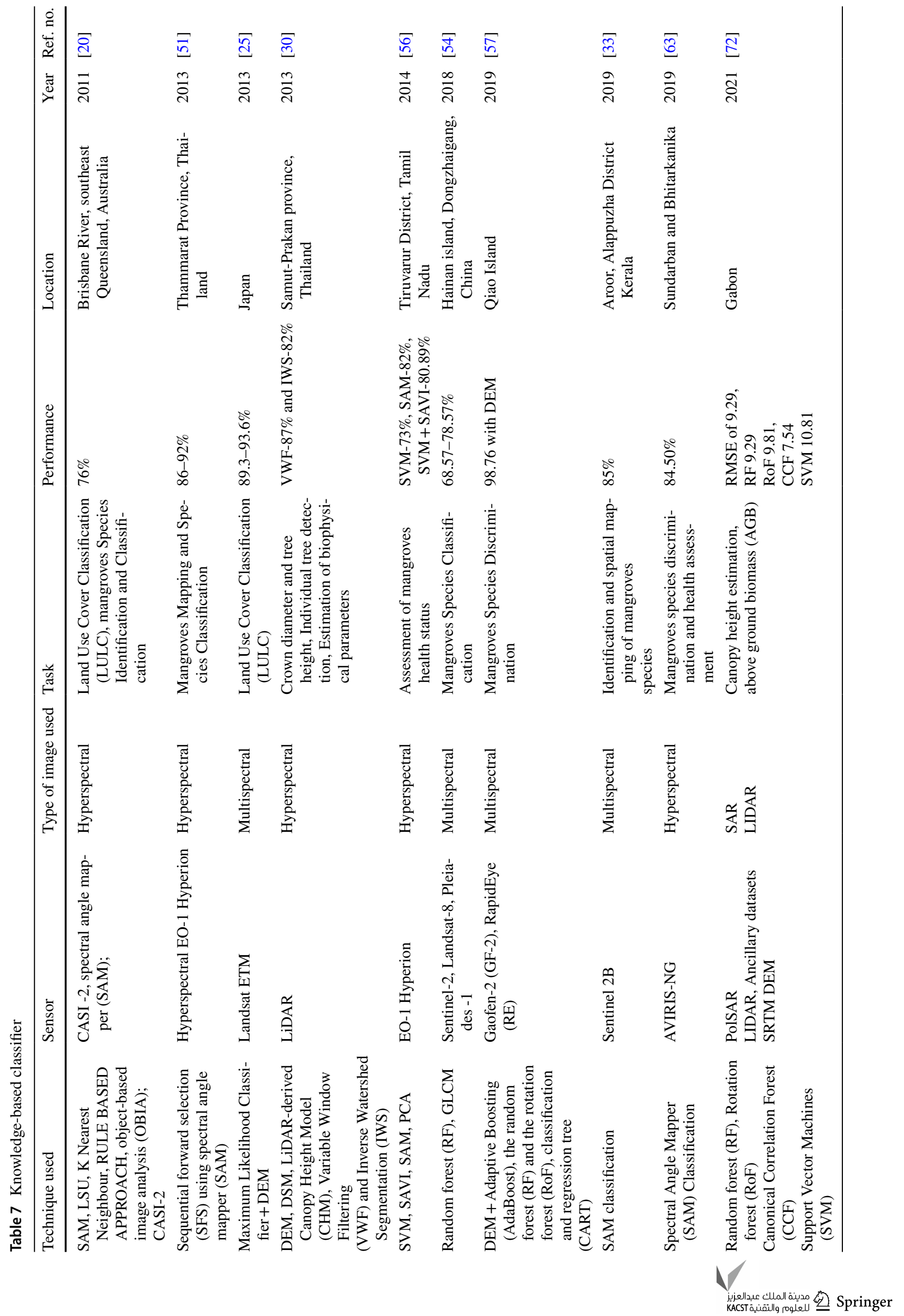


and species classification. Pixel-based supervised machine learning and deep learning-based recent techniques provide high accuracy for mangrove species discrimination by identifying spectral signatures of species with high spatial and spectral resolution data. Most of the past studies have a successful classification for true mangrove species but there are very limited studies for the classification of associate species. So there huge future scope to apply classification approaches on mixed mangrove species and to analyze their performance.

Although object-based supervised machine learning techniques in some cases outperformed pixel-based techniques especially when the hyperspectral image was used. The feature set is most important in machine learning techniques, so when enough features can not be extracted from image data, ancillary data to form explicit rules become handy with knowledge-based classification. Deep learning algorithms can learn the features by themselves and uses artificial neural network algorithms for training data such as backpropagation. From various past studies, it can be concluded that state-of-the-art machine learning and deep learning-based classification approaches seem promising for the study of the mangrove ecosystem with recent developments in pattern recognition and computer vision-based technologies.

Summary and recommendation of various classification techniques to perform a specific mangroves-related task are given in Table 8 with the type of image used and sensor data requirement to serve as future directions in mangrove mapping and monitoring.

Table 8 Summary and recommendation of classification approach

\begin{tabular}{|c|c|c|c|}
\hline The task to be performed & Digital image classification approach & Remote sensing imagery & Recommendation \\
\hline $\begin{array}{l}\text { Land Use Cover Classification } \\
\text { (LULC) } \\
\text { Change Management } \\
\text { mangroves /Non-mangroves Clas- } \\
\text { sification } \\
\text { mangroves Mapping and Monitoring }\end{array}$ & $\begin{array}{l}\text { Unsupervised Classification } \\
\text { ISODATA } \\
\text { K Means } \\
\text { Vegetation Indices } \\
\text { Object-Based Image Analysis } \\
\text { (GEOBIA) }\end{array}$ & $\begin{array}{l}\text { Multispectral } \\
\text { Hyperspectral } \\
\text { SAR } \\
\text { Aerial photograph }\end{array}$ & $\begin{array}{l}\text { When preliminary analysis of the area } \\
\text { is needed for initial studies } \\
\text { Field access is difficult and no suf- } \\
\text { ficient training data available } \\
\text { Data fusion and integration with } \\
\text { Multi-temporal, multi-sensor, and } \\
\text { multi-resolution data } \\
\text { Hyperspectral for small area } \\
\text { Multispectral for large area }\end{array}$ \\
\hline $\begin{array}{l}\text { Spectral Signature Identification } \\
\text { Species Discrimination } \\
\text { Health Assessment } \\
\text { mangroves Biophysical parameters } \\
\text { estimation: } \\
\text { Leaf chlorophyll } \\
\text { Leaf Area Index } \\
\text { Foliar nitrogen concentration }\end{array}$ & $\begin{array}{l}\text { Pixel-based /Object based Supervised } \\
\text { Machine Learning / Deep Learning } \\
\text { Algorithms } \\
\text { Knowledge-based classifier for tex- } \\
\text { ture and feature extraction } \\
\text { Object-Based Image Analysis } \\
\text { (GEOBIA) }\end{array}$ & $\begin{array}{l}\text { Hyperspectral } \\
\text { SAR } \\
\text { LIDAR }\end{array}$ & $\begin{array}{l}\text { High spatial resolution and spectral } \\
\text { resolution } \\
\text { Data fusion and integration with multi- } \\
\text { sensor and multi-resolution data }\end{array}$ \\
\hline $\begin{array}{l}\text { Individual Crown Delineation } \\
\text { Canopy height estimation } \\
\text { Tree Diameter and height Estimation } \\
\text { Above Ground Biomass Estimation }\end{array}$ & $\begin{array}{l}\text { Object-Based Image Analysis (GEO- } \\
\text { BIA), } \\
\text { Pixel-based/ Object based supervised } \\
\text { Machine learning Algorithms/ } \\
\text { Deep learning Algorithms } \\
\text { Knowledge-based classifier } \\
\text { Digital Surface Model (DSM), } \\
\text { Digital Elevation Model (DEM) } \\
\text { Digital Terrain Model (DTM) } \\
\text { Digital Canopy Model (DCM) } \\
\text { LiDAR-derived Canopy height } \\
\text { model (CHM) } \\
\text { ICESat GLAS-derived canopy height }\end{array}$ & $\begin{array}{l}\text { SAR } \\
\text { Hyperspectral } \\
\text { LiDAR }\end{array}$ & $\begin{array}{l}\text { Data fusion and integration with multi- } \\
\text { sensor and multi-resolution data of } \\
\text { SAR and hyperspectral } \\
\text { High spatial and spectral resolution } \\
\text { data }\end{array}$ \\
\hline Mixed Pixel Problem & $\begin{array}{l}\text { Sub Pixel Classification } \\
\text { Object-based Classification } \\
\text { Knowledge-based classification }\end{array}$ & $\begin{array}{l}\text { Multispectral } \\
\text { SAR } \\
\text { Aerial photographs } \\
\text { Hyperspectral } \\
\text { LIDAR }\end{array}$ & $\begin{array}{l}\text { High spatial and spectral resolution } \\
\text { data }\end{array}$ \\
\hline
\end{tabular}




\section{Challenges and future trends in mangroves mapping using remote sensing and digital image classification}

While mapping and monitoring the mangrove ecosystem with remote sensing the distribution of mangrove forest, the area covered, canopy structure, species distribution, and geographical location plays a major role. Remote sensing is mainly to find the spectral signatures of an object from its reflectance characteristics. The reflectance data collected from the signal is the mixture of various components of land classes which need to be classified by appropriate classification to get accurate data for that reasons remote sensing seems to be challenging with various mangrove forest structure, species, and various parameters.

The availability of remote sensing data for a specific location and a specific period is very challenging. It is difficult to have recent data in the context of satellite images as they take time to collect and to be available for end-user. For change management and long-term analysis of mangrove forests, several years of data are needed which sometimes not possible with the single sensor data. There may be different data set available for different periods from different sensors. Now each sensor varies in its spectral and spatial resolution characteristics which need different treatments while applying a classification approach which is one of the challenging tasks to have uniform classification to maintain accuracy. The use of multi-sensor data during change analysis and management shows difficulties in the date of acquisition of images and image processing. The major problem is with the classification of maps from different time points, which sometimes leads to the unavailability of data at that time point in the past generates inaccurate results.

Low to medium spectral resolution image such as multispectral is tend have mixed pixel value for single-pixel which leads to miss classification of data and degrades the performance of classification, therefore mangroves mapping with low to medium spatial resolution sensors such as Landsat is difficult and need extra efforts to work on mixed pixels. The spectral resolution also plays a big role while choosing a sensor for classification because sometimes the number of bands in the sensor limits the differentiation of mangroves species especially when the species are mixed with other species having similar characteristics. The high spatial resolution data can efficiently classify mangrove species and parameters such as hyperspectral and LIDAR, although the cost of the data acquisition and large storage requirement is quite challenging, Furthermore, it can only be applicable for the small areas and the areas for which data is available. Therefore, it suggested using a combination of multi-resolution, multisource data, or multi-fusion data to improve the performance of classification mainly for mangrove species discrimination, mangroves biophysical parameter analysis, and AGB and carbon stock assessment.

The tidal influence on mangrove area is also a big challenge as it changes the spectral signature of mangroves and its effect on canopy height is not fully explored through most of the past studies that need more research. The big tidal fluctuation is going to affect the various parameters of mangroves while assessing through remote sensing. Therefore, knowledge of these variations should be acknowledged and applied in classification through explicit rules for accurate classification. This knowledge will be helpful to analyze long-term changes in mangrove forests, their causes, and more accurate estimates of above-ground biomass and carbon stock.

Pixel-based and object-based machine learning techniques are seemed to be very effective and promising in mangrove species discrimination and extracting parameters such as leaf area index (LAI), tree height, and leaf pigments while used with high spatial resolution optical images such as hyperspectral. Although the disadvantage of optical imageries can overcome by the SAR and LIDAR with data fusion and integration and which would the better choice for analyzing mangrove biophysical parameters and AGB.

The choice of remote sensing data with the classification approach plays a major role, several recommendations for the combination are already mentioned in Table 8 . The future scope of machine learning-based classification is very high with the evolution in artificial intelligence and computer vision for pattern recognition. Furthermore, novel classification techniques based on machine learning also need to be taken into the consideration for future studies. Deep learning techniques are very efficient in identifying spectral bands, therefore accurately classify mangrove species with high-resolution data. Thus, future studies should focus on the choice and development of novel mangrove mapping and monitoring approaches for the mangrove ecosystem.

\section{Conclusion}

The mangrove ecosystem is necessary to coastal communities, however, Mangroves are considered as threatened species all over the globe due to various reasons. Therefore, restoration and conservation of mangroves species are very much important. Mangroves forest covers a massive area and sometimes inaccessible that makes field access a demanding task. This problem can be solved using remote sensing techniques as they provide alternate for mapping and monitoring mangroves and their changes using various classification techniques and a variety of satellite image data and sensors. The present study highlighted significant contributions of remote sensing with various datasets and numerous digital image classification techniques applied to the

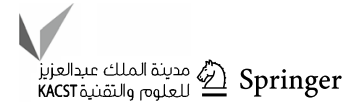


mangrove ecosystem their potential advantages limitations. The study also focused on analyzing various digital image classification approaches, their performance with remote sensing image data and sensors. Based on that future recommendations are also suggested in Table 8 for mapping and monitoring of mangrove ecosystem.

The study concluded that the spectral, spatial, and textural characteristics of an image play a major role in classification. Hyperspectral imagery provides high spatial resolution data and spectral signatures improved the accuracy of the classification and given better results to discriminate between mangroves species for the small scale areas. Furthermore, it had also shown good results mixed-species when used with nonparametric machine learning-based classification techniques. It has also shown improved results while studying various biophysical parameters. Medium spatial resolution information, like the Landsat time-series, are the foremost widely-used for observation of mangrove ecosystem on larger scales. SAR and LIDAR performed very well in estimating tree height, canopy height, and above-ground biomass for mangroves and overcome the disadvantages of optical imagery in classification. SAR data has also the advantage of day and night acquisition.

The current study concludes that the choice of classification approach plays a major role in mapping, monitoring, and mangroves biophysical parameters extraction. High precision mapping results can be obtained by hyperspectral, SAR, and LIDAR datasets. Also, the integration of multiresolution and multi-source image data such as SAR, optical, and LiDAR will be the future scope for the mangrove ecosystem mapping and monitoring to overcome the limitation of individual sensors and to improve the observation accuracy. Furthermore, the advancement in image processing techniques, using pattern recognition and computer vision seems to be promising for the future, especially in machine learning, and deep learning-based classifications for mangroves. Moreover, these techniques are expected to provide improved results in the future with novel approaches.

\section{Declarations}

Conflict of interest On behalf of all authors, the corresponding author states that there is no conflict of interest.

Open Access This article is licensed under a Creative Commons Attribution 4.0 International License, which permits use, sharing, adaptation, distribution and reproduction in any medium or format, as long as you give appropriate credit to the original author(s) and the source, provide a link to the Creative Commons licence, and indicate if changes were made. The images or other third party material in this article are included in the article's Creative Commons licence, unless indicated otherwise in a credit line to the material. If material is not included in the article's Creative Commons licence and your intended use is not permitted by statutory regulation or exceeds the permitted use, you will need to obtain permission directly from the copyright holder. To view a copy of this licence, visit http://creativecommons.org/licenses/by/4.0/.

\section{References}

1. Lu C et al (2018) Dynamic analysis of mangroves forests based on an optimal segmentation scale model and multi-seasonal images in Quanzhou Bay, China. Remote Sens. https://doi.org/10.3390/ rs 10122020

2. Delaine F (2019) Mapping the mangroves forest canopy using spectral unmixing of very high spatial resolution satellite images. Remote Sens. https://doi.org/10.3390/rs11030367

3. Srivastava PK, Mehta A (2019) Assessing impact of climate change on Mundra mangroves forest ecosystem, Gulf of Kutch, western coast of India: a synergistic evaluation using remote sensing. https://doi.org/10.1007/s00704-014-1206-Z

4. Wang D, Wan B, Qiu P, Zuo Z, Wang R (2019) Mapping height and aboveground biomass of mangroves forests on Hainan Island using UAV-LiDAR sampling. Remote Sens 11:2156. https://doi. org/10.3390/rs11182156

5. Heenkenda MK, Joyce KE, Maier SW (2015) Mangroves tree crown delineation from high-resolution imagery. Photogramm Eng Remote Sens 81:471-479. https://doi.org/10.14358/PERS. 81.6.471

6. Rahman M, Lagomasino D, Lee S, Fatoyinbo T, Kanzaki M (2019) Improved assessment of mangroves forests in Sundarbans East Wildlife Sanctuary using WorldView 2 and TanDEM-X high resolution imagery. Remote Sens Ecol Conserv 5:136-149. https://doi.org/10.1002/rse2.105

7. Vo QT, Oppelt N, Leinenkugel P, Kuenzer C (2013) Remote sensing in mapping mangrove ecosystem - an object-based approach. Remote Sens 5(1):183-201. https://doi.org/10.3390/rs5010183

8. Kamal M, Mada UG, Phinn S, Johansen K (2015) Geographic object-based image analysis (GEOBIA) for mangroves tree crown delineation using WorldView-2 image data

9. Kalubarme MH (2014) Mapping and monitoring of mangroves in the coastal districts of Gujarat State using remote sensing and geo-informatics. Asian J Geoinform 14.

10. Zhang C, Kovacs JM, Liu Y, Flores-verdugo F, Flores-de-santiago F (2014) Separating mangroves species and conditions using laboratory hyperspectral data: a case study of a degraded mangroves forest of the Mexican Pacific. Remote Sens 6:11673-11688. https://doi.org/10.3390/rs61211673

11. Mesta P, Setturu B, Rajan KS (2014) Inventorying, mapping and monitoring of mangroves towards sustainable management of West Coast, India. J Remote Sens. https://doi.org/10.4172/21690049.1000130

12. Kamal M, Phinn S, Johansen K (2015) Object-based approach for multi-scale mangroves composition mapping using multiresolution image datasets. Remote Sens 7:4753-4783. https://doi. org/10.3390/rs70404753

13. Pettorelli $\mathrm{N}$ et al (2017) Remote sensing in ecology and conservation: three years on. Remote Sens Ecol Conserv 3(2):53-56. https://doi.org/10.1002/rse2.53

14. Vi C, Vi WG (2016) Mapping and change analysis in mangroves forest by using Landsat imagery. Ann Photogramm Remote Sens Spat Inf Sci 3:12-19. https://doi.org/10.5194/isprs annals-III-8-109-2016

15. Wan L, Zhang H, Lin G, Lin H (2019) A small-patched convolutional neural network for mangroves mapping at species level using high- resolution remote-sensing image. Ann GIS 25(1):4555. https://doi.org/10.1080/19475683.2018.1564791 
16. Heumann BW (2011) An object-based classification of mangroves using a hybrid decision tree-support vector machine approach. Remote Sens 3:2440-2460. https://doi.org/10.3390/rs3112440

17. Thomas N, Bunting P, Lucas R, Hardy A, Rosenqvist A, Fatoyinbo $\mathrm{T}$ (2018) Mapping mangroves extent and change: a globally applicable approach. Remote Sens 10(9):1-20. https://doi.org/10. 3390/rs 10091466

18. Vidhya R, Vijayasekaran D, Farook MA, Jai S, Rohini M, Sinduja A (2017) Improved classification of mangroves health status using hyperspectral remote sensing data. Int Arch Programm Remote Sens Spat Inf Sci. https://doi.org/10.5194/isprsarchi ves-XL-8-667-2014

19. Heenkenda MK, Joyce KE, Maier SW, Bartolo R (2014) Mangroves species identification: comparing WorldView-2 with aerial photographs. Remote Sens 6:6064-6088. https://doi.org/10.3390/ rs6076064

20. Kamal M, Phinn S (2011) Hyperspectral data for mangroves species mapping: a comparison of pixel-based and object-based approach. Remote Sens 3(10):2222-2242. https://doi.org/10.3390/ rs3102222

21. Rosmasita, Siregar VP, Agus SB, Jhonnerie R (2019) An objectbased classification of mangroves land cover using support vector machine algorithm. In: IOP conference series: earth and environmental science, vol 284, no 1. https://doi.org/10.1088/ $1755-1315 / 284 / 1 / 012024$

22. Jhonnerie R, Siregar VP, Nababan B, Prasetyo LB, Wouthuyzen $S$ (2015) Random forest classification for mangroves land cover mapping using Landsat 5 TM and Alos Palsar Imageries. Proc Environ Sci 24:215-221. https://doi.org/10.1016/j.proenv.2015. 03.028

23. Sulong I, Mohd-Lokman H, Mohd-Tarmizi K, Ismail A (2002) Mangroves mapping using Landsat imagery and aerial photographs: Kemaman District, Terengganu, Malaysia. Environ Dev Sustain 4(2):135-152. https://doi.org/10.1023/A:1020844620 215

24. Tieng T, Sharma S, Mackenzie RA, Venkattappa M, Sasaki NK, Collin A (2019) Mapping mangroves forest cover using Landsat-8 imagery, Sentinel-2, very high resolution images and google earth engine algorithm for entire Cambodia. IOP Conf Ser Earth Environ Sci. https://doi.org/10.1088/1755-1315/ 266/1/012010

25. Kobayashi T, Hoan NT (2013) Mangroves forests mapping in the Southern Part of Japan using Landsat ETM + with DEM. J Geogr Inf Syst 5:369-377. https://doi.org/10.4236/jgis.2013. 54035

26. Fatoyinbo TE, Simard M (2013) "Height and biomass of mangroves in Africa from ICESat/GLAS and SRTM. Int J Remote Sens. https://doi.org/10.1080/01431161.2012.712224

27. Kalimantan E, Husna VN, Wibowo PA, Fawzi NI (2019) Identification of mangroves forest change using object-based analysis in Identification of mangroves forest change using object-based analysis in Bontang, East Kalimantan. https://doi.org/10.1088/ 1755-1315/284/1/012037

28. Padma S, Sanjeevi S, Unit RS (2014) Jeffries Matusita-Spectral Angle Mapper (JM-SAM) spectral matching for species level mapping at Bhitarkanika, Muthupet and Pichavaram mangroves. Int Arch Programm Remote Sens Spat Inf Sci 40:9-12. https:// doi.org/10.5194/isprsarchives-XL-8-1403-2014

29. Zuhairi A, Zaleha K, Suhaila NMR, Shaheed MS (2019) Mapping mangroves degradation in Pahang River Estuary, Pekan Pahang by using remote sensing. Sci Herit J 3(2):01-05. https:// doi.org/10.26480/gws.02.2019.01.05

30. Wannasiri W, Nagai M, Honda K, Santitamnont P, Miphokasap $P$ (2013) Extraction of mangroves biophysical parameters using airborne LiDAR. Remote Sens 5(4):1787-1808. https://doi.org/ $10.3390 / \mathrm{rs} 5041787$
31. Abbas S et al (2011) National level assessment of mangroves forest cover in Pakistan. Int Arch Photogramm Remote Sens Spat Inf Sci 3820:187-192

32. Long JB et al (2011) Mapping the Philippines' mangroves forests using Landsat Imagery. Sensors (Basel). https://doi.org/10. $3390 / \mathrm{s} 110302972$

33. Sreekala KC (2019) Bhaskar AS (2019) Identification and spatial mapping of mangroves species using SAM classification a case study from Aroor, Alappuzha District Kerala. Int J RecentTechnol Eng 8(1):B1302-E1306. https://www.srmist.edu.in/ engineering/civil/faculty/draparna-s-bhaskar

34. Pastor-guzman J, Atkinson PM, Dash J, Rioja-nieto R (2015) Spatiotemporal variation in mangroves chlorophyll concentration using Landsat 8. Remote Sens. https://doi.org/10.3390/ rs71114530

35. Fauzi A, Skidmore AK, Van Gils H, Schlerf M, Heitkönig IMA (2013) Shrimp pond effluent dominates foliar nitrogen in disturbed mangroves as mapped using hyperspectral imagery. Mar Pollut Bull 76(1-2):42-51. https://doi.org/10.1016/j.marpolbul. 2013.09.033

36. Zhang C, Kovacs JM, Wachowiak MP, Flores-verdugo F (2013) Relationship between hyperspectral measurements and mangroves leaf nitrogen concentrations. Remote Sens. https://doi. org/10.3390/rs5020891

37. Viennois G et al (2016) Multitemporal analysis of high-spatialresolution optical satellite imagery for mangroves species mapping in Bali, Indonesia. IEEE J Sel Top Appl Earth Obs Remote Sens 9(8):3680-3686. https://doi.org/10.1109/JSTARS.2016. 2553170

38. Ruwaimana M et al (2018) The advantages of using drones over space-borne imagery in the mapping of mangroves forests. PLoS ONE 13(7):1-22. https://doi.org/10.1371/journal.pone.0200288

39. Jia M, Zhang Y, Wang Z, Song K, Ren C (2014) Mapping the distribution of mangroves species in the core zone of Mai Po marshes nature reserve, Hong Kong, using hyperspectral data and high-resolution data. Int J Appl Earth Obs Geoinf 33(1):226-231. https://doi.org/10.1016/j.jag.2014.06.006

40. Id JC, Leng W, Liu K (2018) Object-based mangroves species classification using unmanned aerial vehicle hyperspectral images and digital surface models. Remote Sens. https://doi.org/10.3390/ rs 10010089

41. Wang D, Wan B, Qiu P, Su Y, Guo Q, Wu X (2018) Artificial mangroves species mapping using Pléiades-1: an evaluation of pixel-based and object-based classifications with selected machine learning algorithms. Remote Sens. https://doi.org/10.3390/rs100 20294

42. Pham TD, Tien D, Kunihiko B, Nga Y, Le N (2018) Optimized rule-based logistic model tree algorithm for mapping mangroves species using ALOS PALSAR imagery and GIS in the tropical region. Environ Earth Sci. https://doi.org/10.1007/ s12665-018-7373-y

43. Valderrama-Landeros L, Flores-de-Santiago F, Kovacs JM, Flores-Verdugo F (2018) An assessment of commonly employed satellite-based remote sensors for mapping mangroves species in Mexico using an NDVI-based classification scheme. Environ Monit Assess. https://doi.org/10.1007/s10661-017-6399-z

44. Kovacs JM, De Santiago FF, Bastien J, Lafrance P (2010) An assessment of mangroves in Guinea, West Africa, using a field and remote sensing based approach. Wetlands 30(4):773-782. https:// doi.org/10.1007/s13157-010-0065-3

45. Manjunath KR, Kumar T, Kundu N, Panigrahy S (2013) Discrimination of mangroves species and mudflat classes using in situ hyperspectral data: a case study of Indian Sundarbans. GISci Remote Sens 50(4):400-417. https://doi.org/10.1080/15481603. 2013.814275 
46. Chakravortty S (2013) Analysis of end member detection and subpixel classification algorithms on hyperspectral imagery for tropical mangroves species discrimination in the Sunderbans Delta, India. J Appl Remote Sens. https://doi.org/10.1117/1.JRS.7. 073523

47. Giardino C, Bresciani M, Fava F, Matta E, Brando VE, Colombo R (2016) Mapping submerged habitats and mangroves of Lampi Island Marine National Park (Myanmar) from in situ and satellite observations. Remote Sens 8(1):1-13. https://doi.org/10.3390/ rs8010002

48. Satyanarayana B et al (2018) Status of the undisturbed mangroves at Brunei Bay, East Malaysia: a preliminary assessment based on remote sensing and ground-truth observations. PeerJ 6:1-22. https://doi.org/10.7717/peerj.4397

49. Zhang $\mathrm{H}$ et al (2018) Potential of combining optical and dual polarimetric SAR data for improving mangroves species discrimination using rotation forest. Remote Sens. https://doi.org/10.3390/ rs 10030467

50. Po M, Kong H, Liu M (2018) Zonation and directional dynamics of mangroves forests derived from time-series satellite imagery in Mai Po, Hong Kong. Sustainability. https://doi.org/10.3390/su100 61913

51. Koedsin W, Vaiphasa C (2013) Discrimination of tropical mangroves at the species level with EO-1 hyperion data. Remote Sens 5(7):3562-3582. https://doi.org/10.3390/rs5073562

52. Wong FKK, Fung T (2014) Combining EO-1 Hyperion and Envisat ASAR data for mangroves species classification in Mai Po Ramsar Site, Hong Kong. Int J Remote Sens 35(23):7828-7856. https://doi.org/10.1080/01431161.2014.978034

53. Rogers K, Lymburner L, Salum R, Brooke BP, Woodroffe CD (2017) Mapping of mangroves extent and zonation using high and low tide composites of Landsat data. Hydrobiologia. https://doi. org/10.1007/s10750-017-3257-5

54. Wang D et al (2018) Evaluating the performance of Sentinel-2, Landsat 8 and Pl é iades-1 in mapping mangroves extent and species. Remote Sens. https://doi.org/10.3390/rs10091468

55. Wang T, Zhang H, Lin H, Fang C (2015) Textural-spectral feature-based species classification of mangroves in Mai Po nature reserve from worldview-3 imagery. Remote Sens 8:1-15. https:// doi.org/10.3390/rs8010024

56. Vidhya $R$ et al (2014) Improved classification of mangroves health status using hyperspectral remote sensing data. Int Arch photogramm Remote Sens Spat Inf Sci 40:9-12. https://doi.org/10. 5194/isprsarchives-XL-8-667-2014

57. Peng L et al (2019) Combining GF-2 and RapidEye satellite data for mapping mangroves species using ensemble machine-learning methods Combining GF-2 and RapidEye satellite data for mapping. Int J Remote Sens 00(00):1-26. https://doi.org/10.1080/ 01431161.2019.1648907

58. Lillesand T, Kiefer RW, Chipman J (2015) Remote sensing and image interpretation. Wiley, New York (ISBN 978-1-118-34328-9)

59. Ramsey EW III, Jensen JR (1996) Remote sensing of mangroves wetlands: relating canopy spectra to site-specific data. Photogramm Eng Remote Sens 62:939-948

60. Lewis RR (2005) Ecological engineering for successful management and restoration of mangroves forests. Ecol Eng 24:403-418

61. Chakravortty S, Li J, Plaza A (2018) A technique for subpixel analysis of dynamic mangrove ecosystem with time-series hyperspectral image data. IEEE J Sel Top Appl Earth Obs Remote Sens 11(4):1244-1252. https://doi.org/10.1109/JSTARS.2017. 2782324

62. Debaine F (2019) Mapping the mangroves forest canopy using spectral unmixing of very high spatial resolution satellite images. Remote Sens. https://doi.org/10.3390/rs11030367

63. Chaube NR et al (2019) mangroves species discrimination and health assessment using AVIRIS-NG hyperspectral data. Curr Sci 116(7):1136-1142. https://doi.org/10.18520/cs/v116/i7/ $1136-1142$

64. Manna S, Raychaudhuri B (2018) Mapping distribution of Sundarban mangroves using Sentinel-2 data and new spectral metric for detecting their health condition. Geocarto Int 35(4):434-452. https://doi.org/10.1080/10106049.2018.1520923

65. Hati JP, Samanta S, Chaube NR, Misra A, Giri S, Pramanick N, Gupta K, Majumdar SD, Chanda A, Mukhopadhyay A, Hazra S (2020) Mangrove classification using airborne hyperspectral AVIRIS-NG and comparing with other spaceborne hyperspectral and multispectral data. Egypt J Remote Sens Space Sci. https:// doi.org/10.1016/j.ejrs.2020.10.002

66. Hati JP, Goswami S, Samanta S et al (2020) Estimation of vegetation stress in the mangrove forest using AVIRIS-NG airborne hyperspectral data. Model Earth Syst Environ. https://doi.org/10. 1007/s40808-020-00916-5

67. Baloloy AB, Blanco AC, Ana RRCS, Nadaoka K (2020) Development and application of a new mangrove vegetation index (MVI) for rapid and accurate mangrove mapping. ISPRS J Photogramm Remote Sens 166:95-117. https://doi.org/10.1016/j.isprsjprs. 2020.06.001

68. Wu S, Chen H, Zhao Z, Long H, Song C (2014) An improved remote sensing image classification based on $K$-means using HSV color feature. In: 2014 Tenth international conference on computational intelligence and security, pp 201-204. https://doi.org/10. 1109/CIS.2014.90.

69. Pleșoianu A-I, Stupariu M-S, Șandric I, Pătru-Stupariu I, Drăguț L (2020) Individual tree-crown detection and species classification in very high-resolution remote sensing imagery using a deep learning ensemble model. Remote Sens 12:2426. https://doi.org/ $10.3390 / \mathrm{rs} 12152426$

70. Maung WS, Sasaki J (2021) Assessing the natural recovery of mangroves after human disturbance using neural network classification and Sentinel-2 Imagery in Wunbaik Mangrove Forest. Myanmar Remote Sens 13:52. https://doi.org/10.3390/rs13010052

71. Kanniah KD, Kang CS, Sharma S, Amir AA (2021) Remote sensing to study mangrove fragmentation and its impacts on Leaf Area Index and gross primary productivity in the South of Peninsular Malaysia. Remote Sens 13:1427. https://doi.org/10.3390/rs130 81427

72. Pourshamsi M, Xia J, Yokoya N, Garcia M, Lavalle M, Pottier E, Balzter H (2021) Tropical forest canopy height estimation from combined polarimetric SAR and LiDAR using machine-learning. ISPRS J Photogramm Remote Sens. https://doi.org/10.1016/j.isprs jprs.2020.11.008

Publisher's Note Springer Nature remains neutral with regard to jurisdictional claims in published maps and institutional affiliations. 